Original Research

\title{
Determining Mechanical and Physical Properties of Phospho-Gypsum and Perlite-Admixtured Plaster Using an Artificial Neural Network and Regression Models
}

\author{
Başak Mesci Oktay*, Elif Odabaş \\ Ondokuz Mayis University, Faculty of Engineering, Department of Material Science and Engineering, \\ Samsun, Turkey
}

Received: 8 March 2017

Accepted: 11 April 2017

\begin{abstract}
This research investigates the utilization of artificial neural networks for improving the mechanical and physical properties of phospho-gypsum and perlite-admixtured plaster. The values obtained were modeled using an artificial neural network. Phospho-gypsum $\left(\mathrm{CaSO}_{4} \cdot 2 \mathrm{H}_{2} \mathrm{O}\right)$ is known as a by-product of waste material of the phosphoric acid production process. Perlite is an amorphous volcanic glass. This study examined the effects of perlite and phospho-gypsum additives on fresh and hardened properties of plaster putty and also the feasibility of a plaster with these additives and heat insulation properties. Mixture and physico-mechanical properties after mixture conforming to standards have been provided. The values obtained were modeled with both multiple regression analysis and an artificial neural network. The $\mathrm{R}^{2}$ values for multiple regression analysis with test data were between 0.5264 and 0.9883 . $\mathrm{R}^{2}$ value of the artificial neural network was found to be 0.9907 . The test results of these mixtures have been compared and the plaster mixture with best values was obtained.
\end{abstract}

Keywords: plaster, perlite, phospho-gypsum, ANN

\section{Introduction}

Phosphate fertilizers are produced through the reaction of powdered phosphate rock, including radioactive potassium and radionuclides of naturally existing uraniumradium, and thorium radioactive series with sulphuric acid. Phospho-gypsum $\left(\mathrm{CaSO}_{4} \cdot 2 \mathrm{H}_{2} \mathrm{O}\right)$ is known as a by-product of waste material of the phosphoric acid production process

*e-mail: basakm@omu.edu.tr
[1]. Increasing phospho-gympsum production results in various environmental and radiological problems together with several technological and economical impacts. Such problems directed researchers to find out alternative ways for using them as additive in construction materials. In the construction industry, phospho-gypsum can be used as clinker raw material and as a concrete set retarder in cement production, as a secondary binding material together with cement and lime, and in artificial aggregate production and road stabilization [2-4].

Perlite is an amorphous volcanic glass with acidic characteristics. It expands when heated, and expended 
perlite is quite a light-weight and porous material. Perlite rocks may have different colors and structures. The color of raw perlite may range from transparent light grey to bright black and the colors totally whiten when expended under heat treatment. The most significant characteristic of perlite is about $2-5 \%$ water content as compound to water in hydrated glassy silicate structure and this water provides the stability of perlite. When perlite is heated, all of the free water evaporates at $450^{\circ} \mathrm{C}$, but the structure of the rock doesn't change. When the temperature reached $700-1,200^{\circ} \mathrm{C}$, the effective water in structure of the glass turns into vapor with a couple hundred degrees temperature. It then bursts out of the rock and disappears. With this process, the volume of perlite increases at least four-fold and such an increase may reach 20-fold based on the type of perlite [5-7]. In the construction industry, perlite is used in indoor and outdoor plasters, heat insulation, and construction of water structures since it is resistant to freezing (water insulation of roofs and roof decks, swimming pools, and the manufacture of lightweight construction materials) [8-10].

An artificial neuron network (ANN) is a computational model based on the functions of a biological neural system. ANN can use identifying and modeling data in different forms. It has a wide range of use such as engineering, medicine, and the economy [11-13]. An artificial neural network is an interconnected group of nodes to the vast network of neurons in a brain and it contains simple processing elements called neurons organized into layers. The ANN performs a useful function and it performs the function of nonlinear mapping [14-16].

ANN has many advantages and one of the greatest advantages of artificial neural networks is their capability to learn from their environment. Learning from the environment is useful in applications with complex data [17-18].

An ANN can be used for a variety of tasks such as classification, function approximation, data processing, filtering, clustering, and decision-making. Choosing the right $\mathrm{ANN}$ depends on the type of the application and data representation of a given problem [19, 11, 20].

The present study was conducted to model compressive strength, capillary absorption, water absorption, and flexural strength data obtained with multiple regression analysis and ANNs, and also to identify the method with the most accurate results on the parameters.

\section{Materials and Methods}

\section{Materials}

In the present study we used CEM I 42,5 cement complying with TS EN 197-1 and washed-sieved natural aggregate complying with TS EN 197-1 standards [21]. The phospho-gypsum used in the present experiment was supplied from TÜGSAŞ Fertilizer factory. Samples were
Table 1. Chemical properties of CEM I 42,5 R -type cement, phospho-gypsum, and expended perlite.

\begin{tabular}{|c|c|c|c|}
\hline $\begin{array}{c}\text { Chemical } \\
\text { Composition }\end{array}$ & $\begin{array}{c}\text { CEM I 42,5 } \\
\text { R-type } \\
(\%)\end{array}$ & $\begin{array}{c}\text { Phospho- } \\
\text { gypsum } \\
(\%)\end{array}$ & $\begin{array}{c}\text { Perlite } \\
(\%)\end{array}$ \\
\hline $\mathrm{CaO}$ & 63,81 & 31.48 & 0.60 \\
\hline $\mathrm{SiO}_{2}$ & 18.54 & 0.95 & 71.8 \\
\hline $\mathrm{Al}_{2} \mathrm{O}_{3}$ & 5.25 & 2.45 & 12.9 \\
\hline $\mathrm{Fe}_{2} \mathrm{O}_{3}$ & 2.74 & 0.26 & 0.53 \\
\hline $\mathrm{MgO}$ & 1.85 & 0.54 & 0.17 \\
\hline $\mathrm{SO}_{3}$ & 3.43 & 41.25 & - \\
\hline $\mathrm{P}_{2} \mathrm{O}_{5}$ & - & 0.86 & 0.02 \\
\hline $\mathrm{TiO}_{2}$ & - & 0.11 & - \\
\hline $\mathrm{F}$ & - & 1.43 & - \\
\hline $\mathrm{MnO}$ & - & - & 0.05 \\
\hline $\mathrm{LOI}^{*}$ & 3.57 & 19.21 & - \\
\hline
\end{tabular}

*Loss on ignition

brought to the laboratory, their moisture was removed, and they were subjected to grain-size analysis. In experiments, $200 \mu \mathrm{m}$ grain size was used. Phospho-gypsum samples were composed of $41.25 \% \mathrm{SO}_{3}$ and $31.48 \% \mathrm{CaO}$ (Table 1). Perlite samples were supplied from the Akper Mining Raw Perlite Crashing Sieving and Expansion Integrated Facility. The expended perlite used in this study had fully white color and $0-5 \mathrm{~mm}$ grain size. The unit weight varied between $32-200 \mathrm{~kg} / \mathrm{m}^{3}$. The melting point was $1,300^{\circ} \mathrm{C}$, heat conductance was between 0.034-0.045 Kcal/ $\mathrm{Mh}^{\circ} \mathrm{C}$, and $\mathrm{pH}$ was 6.6-8.0. Chemical properties of CEM I 42,5 R-type cement, phosphogypsum, and expended perlite are provided in Table 1.

\section{Methods}

\section{Plaster Specimens}

Plaster specimens were prepared in accordance with the outdoor plaster preparation principles specified in TS EN 13914-1. Lime was not used since the plasters were prepared for outdoor use. The water was admixtured in accordance with TS EN 196-1 as to have one-half of the cement quantity. Moulds were prepared in accordance with TS EN 196-1, inner surfaces were greased, and plaster samples were placed in these moulds. Half of the moulds were filled with a spatula so as not to have any spaces, and then they were subjected to vibrations 60 times. Then the remaining section was filled and any surplus samples were removed with a spatula. The top of the moulds was covered with glass so as not to have any air. The specimens were set for 24 hours and then the moulds were removed. Then the plaster specimens were placed in curing pools under standard conditions [22-23]. 


\section{Compressive Strength Tests}

The specimens were kept in curing pools for 28 days and then subjected to compressive strength tests at 2,400 $( \pm 200)$ N/s loading rate in accordance with TS EN 196-1. According to TS EN 998-1, compressive strength should be a minimum of $2.5 \mathrm{~N} / \mathrm{mm}^{2}$.

\section{Water Absorption Coefficients}

Admixtures were placed in moulds and cured under standard conditions for 28 days. Then cured specimens were subjected to a capillary absorption test in accordance with the TS EN 772-4 standard for capillary absorption test for construction materials. Specimens were initially dried in an oven and side surfaces were covered with praphine, and they were subjected to water absorption only from the bottom. The $40 \times 40 \times 160 \mathrm{~mm}$ prismatic specimens were dried for 28 days until they reached a constant weight, and their initial weights were determined. Specimens were placed in still water so as to have water contact from the bottom. Then the change in specimen weight and rise in water level was measured [24]. Specimens were weighed at certain time intervals $(0,10,60,100,1,440 \mathrm{~min}$.) and capillary absorption coefficients were calculated using the following equation:

$$
\frac{\mathrm{Q}}{\mathrm{A}}=\mathrm{k} \sqrt{\mathrm{t}}
$$

...where:

$\mathrm{Q}=$ amount of water absorbed by the specimens $\left(\mathrm{cm}^{3}\right)$

$\mathrm{A}=$ surface area of water contact $\left(\mathrm{cm}^{2}\right)$

$\mathrm{k}=$ capillary water absorption coefficient $\left(\mathrm{cm} / \mathrm{s}^{1 / 2}\right)$

$\mathrm{t}=$ time $(\mathrm{s})$

\section{Water Absorption Tests}

The $4 \times 4 \times 16 \mathrm{~cm}$ prismatic specimens were placed in a curing pool for seven days and were dried in an oven until a constant weight. Specimens were immersed into the water and change in weight was measured at different time intervals $(0,10,60,100,1,440 \mathrm{~min}$. $)$

\section{Flexural Strength Tests}

Following the 28-day curing period, specimens were subjected to a flexural strength test with a loading rate of $50( \pm 10) \mathrm{N} / \mathrm{s}$ in accordance with TS EN 196-1 test standard. According to TS EN 998-1, the minimum flexural strength should be $1 \mathrm{~N} / \mathrm{mm}^{2}[22,25]$.

\section{Regression Modeling}

The aim of the multiple regressions is to estimate the relationship between independent variables and a dependent variable. The decision as to which variable in a records set is modeled as the based variable and which might be modeled because the unbiased variables can be based on a presumption that the value of one of the variables is resulting from, or directly inspired with the aid of the other variables. Usually a constant is included as one of the regressors [26].

\section{Artificial Neural Networks Modeling}

The ANN refers to the interconnections among the neurons in the different layers of each system. ANN can be explicitly programmed to carry out a challenge by manually developing the topology and then placing the weights and thresholds of each link. Determining weights is called training. The training data set consists of input signals assigned with a corresponding target [27-28].

Modification of ANN is calculated using an algorithm described as: Each teaching step starts with forcing both input signals from the training set. In this study, the Levenberg-Marquardt (LM) algorithm was used to train the network.

LM is an intermediate optimization algorithm between the Gauss-Newton (GN) method and Gradient descent (GD) algorithm [29]. For LM, the performance index to be optimized is defined as:

$$
e_{k}=\sum_{K=1}^{K}\left(d_{K P}-o_{K P}\right)^{2} \quad k=1 \ldots . . K
$$

...where $\mathrm{k}$ is error vector, $\mathrm{w}=[\mathrm{w} 1 \mathrm{w} 2 \ldots \mathrm{wN}]$, T consists of all weights of the network, $d_{K P}$ is the desired value of the $\mathrm{k}_{\mathrm{th}}$ output and the pth pattern, $\mathrm{o}_{\mathrm{KP}}$ is the actual value of the $k_{\text {th }}$ output and the $p_{\text {th }}$ pattern, $p$ is the number of the pattern, and $\mathrm{K}$ is the number of the network outputs [30]. This algorithm can be considered as a trust-region modification to Gauss-Newton [31]. MATLAB software (Matlab 7.11.0.584 (R2010b)) was used for the artificial neural network.

\section{Results and Discussion}

The present study sought to find the best-fitting $\mathrm{R}^{2}$ value of the ANN and regression models that were compared and thus find a reasonable approach to estimate and improve mechanical and physical properties of phospho-gypsum and perlite mixed plaster. In the multiple regression analysis, compressive strength $\left(\mathrm{Nt} / \mathrm{mm}^{2}\right)$, capillary absorption $\left(\mathrm{cm} / \mathrm{s}^{1 / 2}\right) / 1000$, water absorption, and flexural strength $\left(\mathrm{Nt} / \mathrm{mm}^{2}\right)$ were used as the dependent variables, and phospho-gypsum and perlite were used as the independent variables. The scheme of the artificial neural network is presented in Fig. 1. Best-fitting results were obtained with three input nodes (phospho-gypsum and perlite), one hidden layer with three neurons (which has the logsig function), and one output (CCI). About $70 \%$ of the data set was selected as training data for the ANN model. The output error $(0.007 \mathrm{mse})$ and maximum number of iterations (10 epochs) were determined. 


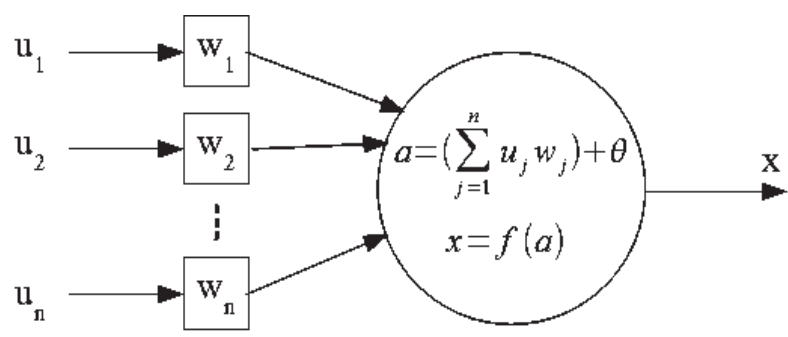

Fig. 1. Scheme of artificial neural network.

The results of regression analysis and artificial neural network are provided in Table 2, which shows compressive strength (CS), capillary absorption (CA), water absorption (WA) and flexural strength (FS). A caption on a single line should be centered.

Regression equations yielded an $\mathrm{R}^{2}$ value of 0.5264 0.9883 (Table 2). $\mathrm{R}^{2}$ value of artificial neural network was identified as 0.9907 , which is the highest value of this research. According to $\mathrm{R}^{2}$ results, artificial neural network model performance was found to be successful in

Table 2. Regression models for the estimation values.

\begin{tabular}{|c|c|c|}
\hline & \multicolumn{2}{|c|}{$\begin{array}{c}\text { Regression } \\
\text { Diagnostics }\left(\mathrm{R}^{2}\right)\end{array}$} \\
\hline $\begin{array}{c}\text { Regression Equations } \\
\text { Fitting } \\
\text { Data }\end{array}$ & $\begin{array}{c}\text { Test } \\
\text { Data }\end{array}$ \\
\hline $\begin{array}{c}(0.272 \times \mathrm{x}) \\
\mathrm{CA}=0.585+(0.029 \times \mathrm{pg})-(0.003 \times \mathrm{p})\end{array}$ & 0.5264 & 0.5342 \\
\hline $\begin{array}{c}\mathrm{WA}=22.73-(0.7767 \times \mathrm{pg})+ \\
(0.7435 \times \mathrm{p})-[0.053 \times(\mathrm{pg} \times \mathrm{p})]\end{array}$ & 0.9883 & 0.9872 \\
\hline $\begin{array}{c}\mathrm{FS}=1.059-(0.0459 \times \mathrm{xpg})- \\
(0.0231 \times \mathrm{p})\end{array}$ & 0.7136 & 0.7252 \\
\hline Artificial Neural Network & - & 0.9907 \\
\hline
\end{tabular}

pg: phospho-gypsum, p: perlite. $\mathrm{R}^{2}$ values are significant at $\mathrm{P}<0.001$

Table 3. Errors in training and testing dataset according to regression and artificial neural network.

\begin{tabular}{|c|c|c|c|c|}
\hline Dataset & Error* & Pg & P & $\begin{array}{c}\text { Artificial } \\
\text { Neural } \\
\text { Network }\end{array}$ \\
\hline \multirow{4}{*}{ Training } & RMS & 0.9273 & 0.3512 & 0.1824 \\
\cline { 2 - 5 } & MAPE & 0.0732 & 0.0351 & 0.0142 \\
\cline { 2 - 5 } & MAE & 0.7224 & 0.2641 & 0.1407 \\
\hline \multirow{3}{*}{ Testing } & RMS & 1.0189 & 0.2961 & 0.2288 \\
\cline { 2 - 5 } & MAPE & 0.0711 & 0.0217 & 0.0161 \\
\cline { 2 - 5 } & MAE & 0.8123 & 0.2244 & 0.1877 \\
\hline
\end{tabular}

* RMS: root-mean-squared error, MAPE: mean absolute percentage error, MAE: mean absolute error describing the relationship between actual and predicted compressive strength, capillary absorption, water absorption, and flexural strength.

As seen in Table 3, the artificial neural network had better results both in training and test error results. While perlite (p) had the least RMSE value (0.3512) yielding the best results in training dataset, the value was 0.1824 in the ANN. Similar findings were observed in MAPE and MAE values. In other words, the ANN yielded the lowest values. This shows that the ANN was successful in predicting compressive strength, capillary absorption, water absorption, and flexural strength values.

The ANOVA results revealed that phospho-gypsum and perlite additives had significant effects on compressive strength, but the interactive effects of phospho-gypsum and perlite were not found to be significant. The effects of only phospho-gypsum on capillary absorption were found to be significant. Besides, the main effects of perlite and interactive effects on phospho-gypsum and perlite were not found to be significant.

The effects of phospho-gypsum and perlite additives and interactive effects of perlite on water absorption were also found to be significant. While the effects of phosphogypsum and perlite additives on flexural strength were found to be significant, interactive effects of phosphogypsum and perlite were not found to be significant. All these interactions are provided in Table 4. Interventions are cited. A caption on a single line should be centered. ANOVA results revealed that the desired plaster characteristics were achieved in the present study.

\section{Conclusions}

This study indicated that it was possible to use ANN to estimate compressive strength, capillary absorption, water absorption, and flexural strength. The research also developed an artificial neural network model that was trained with phospho-gypsum and perlite and compared the model outcomes with the linear regression models. ANN estimated the compressive strength, capillary absorption, water absorption, and flexural strength with higher accuracy, and it can analyze out the model data. When the inputs and outputs of the system were complicated (multiple input and output, nonlinearity, surface defect, and deceases, etc.), with $f$, the help of structural advantages, the ANN could model with high accuracy.

The construction industry is the largest industry in several countries. Further research is recommended for perlite use by the construction industry and for the production of perlite-supplemented plasters with desired commercial attributes. Research is also recommended to solve significant environmental problems through the use of phospho-gypsum, like industrial waste materials in the manufacture of construction materials. In this way, both the waste materials can be regained for the economy and environmental problems can be prevented. In present study, the artificial neural networks model and regression 
Table 4. ANOVA results for compressive strength, capillary absorption, water absorption, and flexural strength.

\begin{tabular}{|c|c|c|c|c|c|c|c|}
\hline & Source & $\begin{array}{c}\text { Degrees } \\
\text { of Freedom }\end{array}$ & $\begin{array}{c}\text { Sum } \\
\text { of squares }\end{array}$ & $\begin{array}{l}\text { Adj. Sum of } \\
\text { squares }\end{array}$ & $\begin{array}{c}\text { Adj. Mean } \\
\text { squares }\end{array}$ & $F$-ratio & P-value \\
\hline \multirow{4}{*}{$\begin{array}{l}\text { Compressive } \\
\text { strength }\end{array}$} & Main effects & 2 & 140.322 & 140.322 & 70.1611 & 20.03 & $<0.001$ \\
\hline & 2-way interaction & 1 & 0.870 & 0.870 & 0.8705 & 0.25 & 0.627 \\
\hline & Residual error & 12 & 42.028 & 42.028 & 3.5024 & & \\
\hline & Total & 15 & 183.221 & & & & \\
\hline \multirow{4}{*}{$\begin{array}{l}\text { Capillary } \\
\text { absorption }\end{array}$} & Main effects & 2 & 0.958 & 0.9582 & 0.4791 & 9.34 & 0.004 \\
\hline & 2-way interaction & 1 & 0.051 & 0.0506 & 0.0506 & 0.99 & 0.34 \\
\hline & Residual error & 12 & 0.616 & 0.6155 & 0.0512 & & \\
\hline & Total & 15 & 1.624 & & & & \\
\hline \multirow{4}{*}{$\begin{array}{c}\text { Water } \\
\text { absorption }\end{array}$} & Main effects & 2 & 753.71 & 753.713 & 376.857 & 601.23 & 0.000 \\
\hline & 2-way interaction & 1 & 45.08 & 45.078 & 45.078 & 71.92 & 0.000 \\
\hline & Residual error & 12 & 7.52 & 7.522 & 0.627 & & \\
\hline & Total & 15 & 806.31 & & & & \\
\hline \multirow{4}{*}{$\begin{array}{l}\text { Flexural } \\
\text { strength }\end{array}$} & Main effects & 2 & 1.018 & 1.0179 & 0.5089 & 20.06 & 0.000 \\
\hline & 2-way interaction & 1 & 0.006 & 0.0062 & 0.0062 & 0.25 & 0.628 \\
\hline & Residual error & 12 & 0.304 & 0.3044 & 0.0253 & & \\
\hline & Total & 15 & 1.329 & & & & \\
\hline
\end{tabular}

models were compared to find the best-fitting $\mathrm{R}^{2}$ value and thus find a reasonable approach to estimate and improve mechanical and physical properties of phospho-gypsum and perlite-mixed plaster.

\section{References}

1. ABDEL-AAL E.A., MAHMOUD M.M.H., EL-SHALL H., ISMAIL A.K. Increasing the filtration rate of phosphogypsum using surfactant, Hydrometallurgy, 85, 53, 2007.

2. GARG M., MINOCHA A.K. JAIN N. Environment hazard mitigation of waste gypsum and chalk: Use in construction materials. Construction and Building Materials, 25, 944, 2011.

3. SINGH M. Influence of blended gypsum on the properties of Portland cement and Portland slag cement. Cement and Concrete Research, 30, 118, 2000.

4. SHEN W., GAN G., DONG R., CHEN H., TAN Y., ZHOU M. Utilization of solidified phosphogypsum as Portland cement retarder. Journal of Material Cycles and Waste Management, 14, 3, 228, 2012.

5. SENGUL O., SENEM AZIZI S., KARAOSMANOĞLU F., TAŞDEMIR M.A. Effect of expanded perlite on the mechanical properties and thermal conductivity of lightweight concrete. Energy and Buildings, 43, 671, 2011.

6. VAOU V., PANIAS D. Thermal insulating foamy geopolymers from perlite. Miner. Eng. 23, 1146, 2010.

7. RASHAD A.M. Synopsis about perlite as building material - A best practice guide for Civil Engineer, Construction and Building Materials, 121, 338, 2016.

8. ROZYCKA A., PICHOR W. Effect of perlite waste addition on the properties of autoclaved aerated concrete,
Construction and Building Materials, 120, 65, 2016.

9. CELIK S., FAMILY R., MENGUC M.P. Analysis of perlite and pumice based building insulation materials, Journal of Building Engineering, 6, 105, 2016.

10. SUN D., WANG L. Utilization of paraffin/expanded perlite materials to improve mechanical and thermal properties of cement mortar. Construction and Building Materials, 101, 791, 2015.

11. CHOPRA P., SHARMA R.K., KUMAR M. Regression models for the prediction of compressive strength of concrete with and without fly ash. Int. J. Latest Trends Eng. Tech., 3 (4), 400, 2014.

12. MASHHADBDAN H., KUTANAEI S.S., SAYARINEJAD M.A. Prediction and modeling of mechanical properties in fiber reinforced self-compacting concrete using particle swarm optimization algorithm and artificial neural network. Construction and Building Materials, 119, 277, 2016.

13. WEGLOWSKI M.S., DYMEK S., HAMILTON C.B. Experimental investigation and modelling of Friction Stir Processing of cast aluminium alloy $\mathrm{AlSi}_{9} \mathrm{Mg}$. Bull. Pol. Ac.: Tech. 61 (4), 893, 2013.

14. ZHOU Q., WANG F., ZHU F. Estimation of compressive strength of hollow concrete masonry prisms using artificial neural networks and adaptive neuro-fuzzy inference systems. Construction and Building Materials, 125, 417, 2016.

15. SIMSEK H., CEMEK B., ODABAS M.S., RAHMAN S. Estimation of Nutrient Concentrations in Runoff from Beef Cattle Feedlot using Adaptive Neuro-Fuzzy Inference Systems. Neural Network World 5 (15), 501, 2015.

16. LOPEZ M.E., RENEA E.R., BOGER Z., VEIGAA M.C., KENNES C. Modelling the removal of volatile pollutants under transient conditions in a two-stage bioreactor using artificial neural networks Journal of Hazardous Materials, 324,100, 2017. 
17. STOJANOVICC B., MILIVOJEVIC M., MILIVOJEVIC N. ANTONIJEVIC D. A self-tuning system for dam behavior modeling based on evolving artificial neural networks. Advances in Engineering Software, 97, 85, 2016.

18. BOSE B.K. Expert System, Fuzzy Logic, and Neural Network Applications in Power Electronics and Motion Control. IEEE Proceedings of the IEEE 82 (8), 1303, 1994.

19. PANDEY D.S., DAS S., PAN I., LEAHY J.J., KWAPINSKI W. Artificial neural network based modelling approach for municipal solid waste gasification in a fluidized bed reactor. Waste Management, 58, 202, 2016.

20. ODABAS M.S., LEELARUBAN N., SIMSEK H., PADMANABHAN G. Quantifying impact of droughts on barley yield in north dakota, usa using multiple linear regression and artificial neural network, Neural Network World, 24, 4, 343, 2014.

21. TS EN 197-1. Cement- Part 1: Composition, specification and conformity criteria for common cements. 2012.

22. TS EN 13914-1. Design, preparation and application of external rendering and internal plastering- Part 1: External rendering. 2016.

23. TS EN 196-1. Methods of testing cement- Part 1: Determination of strength. 2016.

24. TS EN 772-4. Methods of test for masonry units- Part 4: Determination of real and bulk density and of total and open porosity for natural stone masonry units. $\mathbf{2 0 0 0}$.

25. TS EN 998-1. Specification for mortar for masonry- Part 1: Rendering and plastering mortar. 2011.
26. YILDIZ B., BILBAO J.I., SPROUL A.B. A review and analysis of regression and machine learning models on commercial building electricity load forecasting. Renewable and Sustainable Energy Reviews, 73, 1104, 2017.

27. WEIWEI L., WEI S., JIAO W., QI G., LIUA Y. Modelling of adsorption in rotating packed bed using artificial neural networks (ANN). Chemical Engineering Research and Design, 114, 89, 2016.

28. LUZAR M., SOBOLEWSKI L., MICZULSKI W., KORBICZ J. Prediction of corrections for the Polish time scale UTC(PL) using artificial neural networks. Bull. Pol. Ac.: Tech. 61 (3), 589, 2013.

29. ARGYROS I.K., GEORGE S. Expanding the applicability of a modified Gauss-Newton method for solving nonlinear ill-posed problems. Applied Mathematics and Computation 219 (21), 10518, 2013.

30. CUI M., ZHAO Y., XU B., GAO X. A new approach for determining damping factors in Levenberg Marquardt algorithm for solving an inverse heat conduction problem. International Journal of Heat and Mass Transfer, 107, 747, 2017.

31. WANGA P., ZHU D. An inexact derivative-free LevenbergMarquardt method for linear inequality constrained nonlinear systems under local error bound conditions. Applied Mathematics and Computation, 282, 32, 2016. 